\title{
Looking to Australia for help on health care
}

$\mathrm{E}$ ven the most patriotic of Canadians would likely agree that comparing Canada's health care system to those in countries with similar systems could reap benefits. The agreement will end, however, if that comparison is used to recommend an increase in private medical services and health insurance.

The Fraser Institute, a Canadian research and educational organization, has done just that in its new report, Health Care Lessons from Australia. Canada's health care system performs worse than Australia's in many areas, the report states. The institute recommends Canada focus on several areas to more closely emulate Australia, including activity-based funding, cost sharing, private health care insurance and private provision of hospital and surgical services.

"Australia has previously been found in research to be a very high-performing health care system in terms of outcomes," says Nadeem Esmail, author of the report and the institute's director of health policy studies. "In Australia, we find a health care system that makes much greater use of private financing, of private delivery and private competition in health care overall, and that manages to do a better job in providing universal access to health care than does Canada."

Supporters of medicare in Canada aren't so keen on the report's recommendations. Activity-based funding is difficult to implement and provinces would likely place different values on various medical services, increasing regional variations in access to care, says Sandra Azocar, executive director of Friends of Medicare, an advocacy group based in Alberta. She also suggests that cost sharing is merely a means of downloading costs to patients, and more private insurance will push the practice of medicine toward commerce.

"Health care should not be a business," says Azocar. "It's a public service. Everyone is entitled to health care regardless of their ability to pay for insurance."

Dr. Ashley Miller, an internal medicine resident at Memorial University of Newfoundland in St. John's and a board member of Canadian Doctors for Medicare, also cautions against increasing activity-based funding in Canada, citing a lack of evidence to support its benefits. Reached on Twitter, Miller also denounces cost sharing as a "clever synonym for user fees" and suggests that providing adequate oversight of the private provision of health care is a problem.

Her personal belief, she writes, is that "we can achieve improved value without compromising equitable access."

According to Esmail, however, an increased presence of the private sector doesn't spell doom for public health care. "There seems to be this false dichotomy in the debate in Canada," he says. "The defenders of the status quo often claim the false dichotomy as the reason for not moving forward on health care reform. If we do anything to the Canadian health care system, particularly down the roads of more private activity, we must be abandoning universality and adopting an American approach, and that's nonsense."

Though research has shown that Canada does trail Australia in many health performance metrics, including wait times for emergency care and surgery, the Australian system still has its shortcomings, notes Dr. Irfan Dhalla, an assistant professor in the Department of Medicine and the Institute of Health Policy, Management and Evaluation at the University of Toronto in Ontario. Many Australian experts believe their health care system is becoming less equitable, notes Dhalla, and that the rich are receiving favoured treatment. The Fraser Institute may be drawing their conclusions first and finding evidence later, suggests Dhalla.

"It's very difficult to compare waiting list data from two different jurisdictions, but it's pretty clear that public sector wait times for procedures like joint replacements are a big problem in Australia too," Dhalla writes in an email.

Recommendations aside, there is indeed much to learn from other countries about health care, says Anne Snowdon, chair of the Ivey International Centre for Health Innovation at

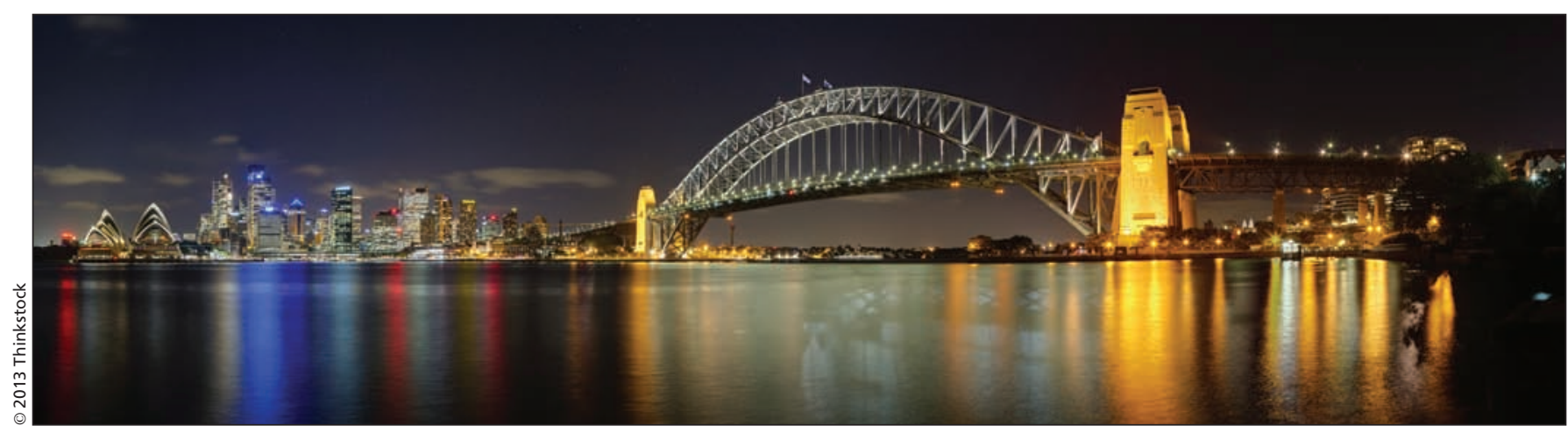

Research indicates that Canada does trail Australia in many health performance metrics, including wait times for emergency care and surgery, but, say some experts, the Australian system still has its shortcomings. 
Western University in London, Ontario. Australia is a particularly good comparator, she suggests, because of its similar governance structure. In Australia, individual states are in charge of their health care systems, just as provinces are in Canada. The two nations also face similar obstacles in providing care to their populations.

"Australia is an interesting comparator because they face the same challenge we do of having a very large landmass and a small population distributed widely," says Snowdon. "So the whole issue of access to care in remote and rural communities is a challenge for Australia just as it is for us."
The Fraser Institute's report did not focus enough on the most important lesson to be learned from the Australian health system, says Snowdon, who has contributed to papers comparing Canada's health system to those of other countries, including Australia.

Most general practitioners in Australia belong to a local Division of General Practice. These divisions allow family doctors to coordinate to meet the needs of local populations and have improved access to after-hours care. In Canada, by contrast, people tend to visit emergency departments outside of working hours because of lack of access to primary care.
"When you look at those recommendations, I don't see how any of that will drive transformational change in health systems. They are recommending ideas that are already, to some degree, moving and in place in many of the provinces," says Snowdon.

"They pull out the importance of the private health care and the health care insurance for medically necessary care," she adds. "But the real attribute I see as so valuable to learn from in Australia is $24 / 7$ access, regardless of how rural and remote your community." Roger Collier, CMAJ

CMAJ 2013. DOI:10.1503/cmaj.109-4421 